\title{
Efficiency of Expansion Sphincter Pharyngoplasty in the Treatment of Obstructive Sleep Apnea Syndrome
}

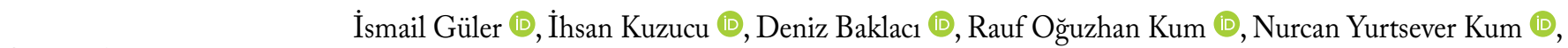 \\ Müge Özcan (D) \\ Department of Otorhinolaryngology, Ankara Numune Training and Research Hospital, Ankara, Turkey
}

\section{Abstract}

ORCID IDs of the authors: i.G. 0000-0001-6093-6757; I.K. 0000-0001-5773-4126; D.B. 0000-0001-8449-4965; R.0.K. 0000-0002-9639-0204; N.Y.K. 0000-0002-7528-8294; M.0. 0000-0003-2384-3564.

Cite this article as: Güler I, Kuzucu I, Baklacı D Kum RO, Yurtsever Kum N, Özcan M. Efficiency of Expansion Sphincter Pharyngoplasty in the Treatment of Obstructive Sleep Apnea Syndrome. Turk Arch Otorhinolaryngol 2018; 56(4):206-9.

\section{Corresponding Author:} İsmail Güler; dr.ismailguler@gmail.com

Received Date: 08.07.2018 Accepted Date: 21.10.2018 Available Online Date: 21.12.2018

(c) Copyright 2018 by Official Journal of the Turkish Society of Otorhinolaryngology and Head and Neck Surgery Available online at www.turkarchotolaryngol.net DOI: 10.5152/ta0.2018.3665
Objective: Obstructive sleep apnea syndrome (OSAS) is characterized by recurrent episodes of upper respiratory-tract obstruction during sleep and decrease in arterial oxygen saturation. Expansion sphincter pharyngoplasty (ESP) is a simple, safe, and effective method for the surgical treatment of OSAS. The aim of our study was to evaluate the efficacy of ESP with polysomnography (PSG) in OSAS patients.

Methods: This study was conducted on patients referred to our center for the treatment of snoring, apnea, witnessed apnea, and daytime sleepiness during 20102018. Overall, 67 patients (16 females, 51 males) who had PSG test at postoperative three months and were considered suitable with history, physical examination, and surgery after PSG were included in the study. Patients were classified into three groups according to OSAS severity: mild, moderate, and severe. Patient age, sex, body mass index (BMI), pre- and postope- rative period apnea-hypopnea index (AHI), Epworth sleepiness scores, and PSG data were recorded.

Results: The mean BMI of all groups was $27.44 \pm 2.73$. The postoperative AHI decreased from $18.26 \pm 2.23$ to $8.01 \pm 0.97(p<0.001)$. Surgical success rate was $67.2 \%$; it was higher in females $(p=0.047)$. The highest success rate was found in the mild OSAS group; however, this difference was not statistically significant when compared to the other groups $(\mathrm{p}=0.217)$. There were statistically significant improvement at postoperative Epworth sleepiness scores and minimum $\mathrm{O}_{2}$ saturations $(\mathrm{p}<0.001$ and $\mathrm{p}=0.018$, respectively).

Conclusion: ESP is an effective and successful surgery in selected patients with lateral pharyngeal and retropalatal narrowing.

Keywords: Obstructive sleep apnea syndrome, polysomnography, expansion pharyngoplasty, surgery

\section{Introduction}

Snoring is considered a social problem that disrupts the person's sleep quality and causes problems among spouses. Snoring is caused by the vibration of the structures-the soft palate, the uvula, the tonsils, the tongue base, the epiglottis and the pharyngeal walls-in the oral cavity and the oropharynx. Many doctors who deal with sleep disorders believe snoring to be a complaint warning about a possible obstructive sleep apnea syndrome (OSAS) (1). OSAS is characterized by repeated obstruction attacks in the upper respiratory tract during sleep and often by decreased arterial oxygen saturation levels (2). OSAS is a common sleep disorder. In a study conducted with 602 volunteers who underwent polysomnography the incidence of sleep-disordered breathing was found $24 \%$ among males and $9 \%$ among females, of which most had not been already diagnosed (3). Of the individuals who actually have OSAS, $93 \%$ of the females and $82 \%$ of the males are estimated to be undiagnosed (4). While initially considered an insignificant public health problem, OSAS, with a prevalence of 6 to $13 \%$, is identified to be almost as common as conditions like hypertension, coronary artery disease $(2,5)$.

Polysomnography (PSG), despite being costly and time-consuming, and requiring special equipment and trained staff, is the gold standard test for diagnosis of OSAS (6). Several techniques have been described and are used in the treatment of OSAS. Most of these techniques aim at creating fibrosis on the palate through scarring, and thereby reducing vibration by stiffening the palate. The first palatal fibrosis surgery was performed in 1994, after which 
the procedure was improved with a range of modifications $(7,8)$. These include the expansion sphincter pharyngoplasty (ESP) surgery described by Pang and Woodson (9) targeting the oropharynx. As a result of the reported successful outcomes this technique has become one of the most commonly used surgical interventions today. In this study, we aimed to evaluate the surgical outcomes of the ESP technique in our OSAS patients with PSG.

\section{Methods}

Patients who underwent an ESP surgery in our clinic between January 2010 and January 2018 were retrospectively reviewed. Approval was obtained from the Ethics Committee of the Ankara Numune Training and Research Hospital (Ethics Committee Approval Nr: E-18-1863). Patients who were diagnosed with OSAS through PSG and underwent an ESP surgery in our clinic were specified and their files were reviewed. Patients included in the study were aged over 18 years, had no comorbidities, had a body mass index (BMI) of less than $35 \mathrm{~kg} / \mathrm{m}^{2}$, were identified as stage 2 or stage 3 according to the anatomic staging system developed by Friedman et al. (10), and were examined with PSG at least three months after the surgery. Patients aged over 60 years, had comorbidities, had previously undergone a palatal or a tongue base surgery, or had distinct base-of-tongue collapse were excluded from the study.

Upper respiratory tracts were endoscopically examined, and collapse sites were evaluated in all patients: All patients were examined under local anesthesia (4\% lidocaine and $0.5 \%$ ephedrine spray) in seated position by flexible transnasal endoscopy (Olympus ENF Type GP, Hamburg, Germany). Patients who had no distinct base-of-tongue pathologies but had lateral pharyngeal wall collapse were included in the assessment.

Polysomnography was performed in the single-bed rooms of the sleep center of our hospital during spontaneous sleep and under the supervision of a sleep technician. Audio and visual recording was made throughout the night. An Alice 5 Model PSG device (Philips Respironics, Best, The Netherlands) was used in the study. Electroencephalogram, submental and bilateral tibialis anterior electromyogram, electrooculogram signals, nasal airflow, thoracic and abdominal respiratory effort, blood oxygen saturation (pulse oximetry) and body positions were recorded. PSG data were evaluated by an otorhinolaryngologist holding PSG certification according to the guidelines of the American Academy of Sleep Medicine. At least 10 seconds of pause in respiration during sleep was defined as sleep apnea. At least 3\% decrease in oxygen saturation together with at least $50 \%$ decrease in respiratory volume and decline in chest wall mobility and/or arousal was defined as hypopnea. Apnea-hypopnea index (AHI) value was calculated by dividing the sum of apnea and hypopnea counts recorded during sleep into the total sleeping time. $\mathrm{Pa}-$ tients were classified based on their AHI scores: simple snoring, AHI $<5$; mild OSAS, $5 \leq \mathrm{AHI}<15$; moderate OSAS, $15 \leq \mathrm{AHI}$ $<30$; and severe OSAS, AHI $\geq 30$.

Effectiveness of the expansion sphincter pharyngoplasty in patients were assessed based on the PSG results recorded in the postoperative third month. Post-surgical success was determined as postoperative $\mathrm{AHI}<20$ and $50 \%$ reduction in $\mathrm{AHI}$ ) (9). Success rates by OSAS severity, changes in Epworth Sleepiness Scale and variations in minimum $\mathrm{O}_{2}\left(\mathrm{minO}_{2}\right)$ were recorded.

In all patients the expansion sphincter pharyngoplasty surgery was performed under general anesthesia and in supine position. Oral cavity was visualized by drawing the endotracheal tube forward with a Boyle-Davis mouth gag, and bilateral tonsillectomy was performed. After the palatopharyngeus muscle was identified, its inferior end was horizontally incised and dissected over the posterior superior pharyngeal constrictor muscle up to the upper pole of the tonsil, then the free end was sutured with an 8 -shaped suture using 3/0 Vicryl. A tunnel was prepared from the soft palate muscles, and the palatopharyngeus muscle was brought to the antero-superolateral end through the tunnel and fixed. Partial uvulectomy was performed in patients with a long uvula (11).

Statistical analysis was performed using the Statistical Package for Social Science for Windows version 21.0 (IBM Corp.; Armonk, NY, USA) software. Pre- and postoperative values of the study group were analyzed using the Student's T Test for parametric data and the Mann-Whitney $U$ Test for nonparametric data. A p value less than 0.05 was accepted as significant.

\section{Results}

Eight-one patients were identified to have undergone ESP in our clinic in the specified period, and 67 patients who matched the inclusion criteria (51 males [76.1\%] and 16 females [23.9\%]) were included in the study. In this group mean patient age was $45.55 \pm 9.53$ years, and all patients had a preoperative BMI of $27.44 \pm 2.73 \mathrm{~kg} / \mathrm{m}^{2}$ and AHI of $18.26 \pm 2.23$. Of the patients included in the study, 39 patients (58.2\%) had mild OSAS, 12 patients (17.9\%) had moderate OSAS, and 16 patients (23.9\%) had severe OSAS. Preoperative data and demographic details of patients are given in Table 1.

Mean BMI was found $27.20 \pm 2.33 \mathrm{~kg} / \mathrm{m}^{2}$ in the postoperative third month examination of the patients. No statistically significant differences were found when compared to preoperative $\mathrm{BMI}$ values $(\mathrm{p}=0.509)$. Postoperative AHI was found $8.01 \pm 0.97$ in all patients $(\mathrm{p}=0.001)$. The overall success rate following expansion sphincter pharyngoplasty surgeries was found $67.2 \%$. Surgical success rates by gender are $87 \%(14 / 16)$ in female patients and $60.8 \%(31 / 51)$ in male patients $(\mathrm{p}=0.047)$ (Table 2$)$.

While mean preoperative $\operatorname{minO}_{2}$ saturation was $83.90 \pm 5.72$, this value was found $88.65 \pm 6.48$ after the expansion sphincter pharyngoplasty surgeries. The difference between pre- and postoperative $\mathrm{minO}_{2}$ saturation values were statistically significant $(\mathrm{p}=0.018)($ Table 2$)$.

While Epworth Sleepiness Scale scores were $8.25 \pm 4.84$ before the surgeries, these were seen to have decreased to $5.56 \pm 3.19$ after the surgeries $(\mathrm{p}=0.001)$ (Table 2). 
Success rates were $74.4 \%$ ( 29 in 39 ) in patients with mild OSAS; $66.7 \%$ (8 in 12) in patients with moderate OSAS; and 50\% (8 in 16) in patients with severe OSAS. While the highest success rate was achieved in the mild OSAS group, no statistically significant differences were found among the groups in terms of success $(\mathrm{p}=0.217)($ Table 3$)$.

\section{Discussion}

Severe daytime sleepiness and loud snoring are the major signs of OSAS, which can often go unnoticed and can lead to severe medical complications when left untreated (12-14).

Patients with OSAS mostly suffer multilevel obstruction in the palate, lateral pharyngeal wall and the tongue base. All areas, including lateral pharyngeal wall collapse, should be addressed

Table 1. Distribution of patient characteristics

\begin{tabular}{l|l|c|c}
\hline \multicolumn{3}{|c}{ n } & $\%$ \\
\hline Gender & Female & 16 & 23.9 \\
& Male & 51 & 76.1 \\
\hline OSAS grade & $\begin{array}{l}\text { Mild } \\
\text { (mean AHI) }\end{array}$ & $39(9.74)$ & 58.2 \\
& $\begin{array}{l}\text { Moderate } \\
\text { (mean AHI) }\end{array}$ & $12 /(19.88)$ & 17.9 \\
& $\begin{array}{l}\text { Severe } \\
\text { (mean AHI) }\end{array}$ & $16 /(34.85)$ & 23.9 \\
\hline Age $(\mathbf{y r s})$ & Female $($ mean \pm SD) & Male $($ mean \pm SD) \\
BMI $\left(\mathrm{kg} / \mathrm{m}^{2}\right)$ & & $49.85 \pm 6.56$ & $44.16 \pm 5.23$ \\
AHI & & $27.67 \pm 2.96$ & $27.22 \pm 2.50$ \\
Min $\mathrm{O}_{2}$ & & $16.1 \pm 2.18$ & $18.9 \pm 3.48$ \\
\hline BHI & & $83.82 \pm 10.62$ & $84.71 \pm 12.18$ \\
\hline
\end{tabular}

BMI: body mass index; AHI: apnea-hypopnea index (event/hr); $\min \mathrm{O}_{2}$ : minimum oxygen saturation; OSAS: obstructive sleep apnea syndrome

Table 2. Comparison of pre- and postoperative AHI and BMI values, and OSAS success rates by gender

\begin{tabular}{l|c|c|c}
\hline & Preoperatif & Postoperatif & $p$ \\
\hline BMI $\left(\mathrm{kg} / \mathrm{m}^{2}\right)$ & $27.44 \pm 2.73$ & $27.20 \pm 2.33$ & 0.509 \\
$\mathrm{AHI}$ & $18.26 \pm 2.23$ & $8.01 \pm 0.97$ & 0.001 \\
$\mathrm{Min} \mathrm{O}_{2}$ & $83.90 \pm 5.72$ & $88.65 \pm 6.48$ & 0.018 \\
Epworth score & $8.25 \pm 4.84$ & $5.56 \pm 3.19$ & 0.001 \\
\hline Treatment success & Female & Male & \\
(Total 67.2\%) & $14 / 16(87 \%)$ & $31 / 51(60.8 \%)$ & 0.047
\end{tabular}

BMI: body mass index; AHI: apnea-hypopnea index (event/hr); $\min \mathrm{O}_{2}$ : minimum oxygen saturation

Table 3. Assessment of surgical success rates by OSAS severity Mild OSAS Moderate OSAS Severe OSAS p

\begin{tabular}{l|l|l|l|l|}
\hline Success & $29 / 39(74.4 \%)$ & $8 / 12(66.7 \%)$ & $8 / 16(50 \%)$ & 0.217
\end{tabular}

OSAS: obstructive sleep apnea syndrome in the surgical treatment of OSAS in these patients. Lateral pharyngeal walls will be more flexible and collapsible under air pressure in patients with OSAS than in healthy individuals. Furthermore, lateral pharyngeal walls will be thicker in OSAS patients and constitute a major anatomic factor leading to the narrowing of the airway (15).

Cahali (16) has described a lateral pharyngoplasty procedure in 10 patients who had moderate or severe OSAS and in which lateral pharyngeal wall collapse was identified during clinical endoscopic examination. While the patients had a mean AHI value of 45.8 before the procedure, this value is reported to have decreased to 15.2 in postoperative eighth month.

Expansion sphincter pharyngoplasty was described by Pang and Woodson (17) to advance this surgical technique in order to avoid issues such as dysphagia and velopharyngeal insufficiency experienced in lateral pharyngoplasty. In this technique, the palatopharyngeus muscle is dissected and rotated superiorly and anterolaterally. Achieving fibrosis in the superior pharyngeal constrictor muscle is critical. Full or partial uvulectomy can be performed in this procedure $(11,17)$.

In their randomized controlled study, Pang et al. (9) accepted a decrease to below $50 \%$ compared to the preoperative AHI level and an AHI level of less than 20 as success criteria in their follow-up of their ESP surgery patients. Accordingly, the authors report a success rate of $82.6 \%$ for the surgery.

In a study, Carrasco et al. (18) treated their patients in two groups and performed ESP surgery in one group and conventional uvulopalatopharyngoplasty surgery in the other. Based on preoperative $\mathrm{AHI}$ values the authors report a better success rate in the ESP group.

Vicini et al. (19), in their study, report that the mean preoperative AHI value of $19.8 \pm 14.1$ of their patients improved to a mean 9.9 \pm 8.6 after ESP and transoral robotic surgery (tongue base resection). Having used the lateral pharyngoplasty technique in patients with lateral pharyngeal collapse, Pang (20) reports this technique to be an effective method that can be used alone or in multilevel surgical procedures.

In a recent study Karakoç et al. (20) compared the effectiveness of anterior palatoplasty, Cahali's lateral pharyngoplasty and ESP techniques. In conclusion the authors report that while all techniques were effective in selected OSAS patients, the ESP technique was one step ahead of the other two techniques. In our study, the success rate of ESP in our surgical patients was $67.2 \%$. Mild OSAS patients were seen to have more benefited from the procedure and $\mathrm{minO}_{2}$ saturation levels were observed to have increased in line with our success rates.

Apart from the improvement in postoperative AHI levels, Pang et al. (21) also report to have assessed the Epworth Sleepiness Scores and found that the mean 16.2 score had decreased to 7.9 after the ESP surgery. Likewise, in our study, the Epworth 
Sleepiness score significantly decreased after the surgery. We believe that a statistically significant decrease in the Epworth Sleepiness score is another result that demonstrates the effectiveness of the surgery.

The low number of study patients and the lack of drug-induced sleep endoscopy in all patients are the limiting aspects of this study. In this regard, we suggest that further multidisciplinary and prospective studies should be conducted with larger patient groups.

\section{Conclusion}

In our study, we found an overall success rate of $67.2 \%$ among our OSAS patients who underwent an ESP surgery. Regarding the preoperative severity levels of the condition in all patients, those with mild OSAS were observed to have benefited more from the procedure and had increased $\mathrm{minO}_{2}$ saturation levels along with decreased Epworth scores.

Ethics Committee Approval: Ethics committee approval was received from the Ethics Committee of Ankara Numune Training and Research Hospital (E-18-1863).

Informed Consent: Informed consent was not received due to the retrospective nature of the study.

Peer-review: Externally peer-reviewed.

Author Contributions: Concept - İ.G., R.O.K., İ.K., D.B., N.Y.K., M.Ö.; Design - İ.G., R.O.K., İ.K., D.B., N.Y.K., M.Ö.; Supervision - İ.G., R.O.K., İ.K., D.B., N.Y.K., M.Ö.; Resource - R.O.K., İ.K., N.Y.K., I.G., D.B.; Materials - R.O.K., I.K., N.Y.K.; Data Collection and/or Processing - R.O.K., I.G., N.Y.K.; Analysis and/or Interpretation - R.O.K., İ.K., İ.G., D.B.; Literature Search - R.O.K., İ.K. İ.G., D.B.; Writing - R.O.K., D.B., N.Y.K., I.G.; Critical Reviews - N.Y.K., M.Ö.

Conflict of Interest: The authors have no conflicts of interest to declare.

Financial Disclosure: The authors declared that this study has received no financial support.

\section{References}

1. Pang KP, Tan R, Puraviappan P, Terris DJ. Anterior palatoplasty for the treatment of OSA: three-year results. Otolaryngol Head Neck Surg 2009; 141: 253-6. [CrossRef]

2. Spicuzza L, Caruso D, Di Maria G. Obstructive sleep apnoea syndrome and its management. Ther Adv Chronic Dis 2015; 6: 27385. [CrossRef]

3. Young T, Palta M, Dempsey J, Skatrud J, Weber S, Badr S. The occurrence of sleep-disordered breathing among middle-aged adults. N Engl J Med 1993; 328: 1230-5. [CrossRef]

4. Young T, Evans L, Finn L, Palta M. Estimation of the clinically diagnosed proportion of sleep apnea syndrome in middle-aged men and women. Sleep 1997; 20: 705-6. [CrossRef]
5. Peppard PE, Young T, Barnet JH, Palta M, Hagen EW, Hla KM. Increased prevalence of sleep-disordered breathing in adults. Am J Epidemiol 2013; 177: 1006-14. [CrossRef]

6. Epstein LJ, Kristo D, Strollo PJ, Friedman N, Malhotra A, Patil $\mathrm{SP}$, et al. Clinical guideline for the evaluation, management and long-term care of obstructive sleep apnea in adults. J Clin Sleep Med 2009; 5: 263-76.

7. Ellis P. Laser palatoplasty for snoring due to palatal flutter: a further report. Clin Otolaryngol Allied Sci 1994; 19: 350-1. [CrossRef]

8. Mair LEA, Day CRH, Holt GR. Cautery-assisted palatal stiffening operation. Otolaryngol Head Neck Surg 2000; 122: 547-56. [CrossRef]

9. Pang KP, Woodson BT. Expansion sphincter pharyngoplasty: a new technique for the treatment of obstructive sleep apnea. Otolaryngol Head Neck Surg 2007; 137: 110-4. [CrossRef]

10. Friedman M, Ibrahim H, Joseph NJ. Staging of obstructive sleep apnea/hypopnea syndrome: a guide to appropriate treatment. Laryngoscope 2004; 114: 454-9. [CrossRef]

11. Suslu AE, Pamuk G, Pamuk AE, Ozer S, Jafarov S, Onerci TM. Effects of expansion sphincter pharyngoplasty on the apnea-hypopnea index and heart rate variability. J Oral Maxillofac Surg 2017; 75: 2650-7. [CrossRef]

12. Sullvan C. Reversal of obstructive sleep apnea by continuous positive airway pressure applied through the nares. Lancet 1981; 1 : 862-5. [CrossRef]

13. Riley RW, Powell NB, Guilleminault C. Obstructive sleep apnea syndrome: a review of 306 consecutively treated surgical patients. Otolaryngol Head Neck Surg 1993; 108: 117-25. [CrossRef]

14. Powell NB. Contemporary surgery for obstructive sleep apnea syndrome. Clin Exp Otorhinolaryngol 2009; 2: 107. [CrossRef]

15. Schwab RJ, Gupta KB, Gefter WB, Metzger LJ, Hoffman EA, Pack AI. Upper airway and soft tissue anatomy in normal subjects and patients with sleep-disordered breathing. Significance of the lateral pharyngeal walls. Am J Respir Crit Care Med 1995; 152: 1673-89. [CrossRef]

16. Cahali MB. Lateral pharyngoplasty: a new treatment for obstructive sleep apnea hypopnea syndrome. Laryngoscope 2003; 113: 1961-8. [CrossRef]

17. Pang KP, Woodson BT. Expansion sphincter pharyngoplasty: a new technique for the treatment of obstructive sleep apnea. Otolaryngol Head Neck Surg 2007; 137: 110-4. [CrossRef]

18. Carrasco-Llatas M, Marcano-Acu-a M, Zerpa-Zerpa V, Dalmau-Galofre J. Surgical results of different palate techniques to treat oropharyngeal collapse. Eur Arch Otorhinolaryngol 2015; 272: 2535-40. [CrossRef]

19. Vicini C, Montevecchi F, Pang K, Bahgat A, Dallan I, Frassineti S, et al. Combined transoral robotic tongue base surgery and palate surgery in obstructive sleep apnea-hypopnea syndrome: Expansion sphincter pharyngoplasty versus uvulopalatopharyngoplasty. Head Neck 2014; 36: 77-83. [CrossRef]

20. Karakoc O, Binar M, Aydin U, Genc H, Akcam T, Gerek M. A tertiary center experience with velopharyngeal surgical techniques for treatment of snoring and obstructive sleep apnea. Auris Nasus Larynx 2018; 45: 492-8. [CrossRef]

21. Pang KP, Piccin O, Pang EB, Pang KA, Chan YH, Rotenberg BW. Combined expansion pharyngoplasty and anterior palatoplasty for the treatment of OSA. Indian J Otolaryngol Head Neck Surg 2016; 68: 528-33. [CrossRef] 